\title{
FORMULATIONS FOR GLASS PAINT USING LOCAL PAINTS
}

\author{
Shaima Salama Ibrahim DESOUKI*
}

Glass Department, Faculty of Applied Arts, Helwan University, Egypt

\begin{abstract}
Painting is one of the most important arts that highlight the civilization of peoples, and it is one of the important means For expressing human experience and transferring knowledge across generations, photography has gone through stages Various and multiple developments, and the history of imaging on glass and its spread goes back to me The middle of the twelfth century AD, although most historians refer to the art of painting On glass for very ancient times, photography on glass depends on the ability of Designed on creativity, using a variety of materials and tools to obtain aesthetic values To photograph in his artistic works of glass, in which many glass artists have excelled It is known that local glass colorants have limited capabilities and have limited capabilities The surface appearance is less lustrous than the glass colorants produced worldwide in photography On the glass.

Keywords

Formulations, Glass, Paint, Local.
\end{abstract}

\section{Introduction}

\section{Research Problem:}

1- How to make use of homemade colorants Shoot on glass surfaces and get the best of it Graphic results?

2- Can the local colorants match the appearance of a surface? Glass produced using colorants produced internationally?

3- What are the most important aesthetic and technological considerations? To photograph on glass with local colourants?

\section{The goals of research}

1- Reaching the best aesthetic and technological features for local colorants.

2- Creating innovative visual formulas to depict on Glass surface using local colorants.

3- Determine the most important aesthetic and technological considerations of the photography on the surface of the glass.

\section{Hypothesis:}

-It is by using local colorants in the photography operations, it can be applied on glass surfaces by different means, obtaining new collages of art

on glass, it enriches the creative process and is as impressive as it looks

Global colourants.

\section{Research Methodology:}

The research follows an experimental method.

\footnotetext{
*Corresponding author: appliedarts@a-arts.helwan.edu.eg
} 


\section{Application technology}

Thin and wide brushes

Used equipment

A work of art simulating a sunset behind wheat ears, which was executed in two stages, the first stage is to define the details and movement of wheat ears in black color to be fixed with heat.

To ensure its stability on the surface, Stage Two is to complete the background with a wide brush.

To create the gradient that illustrates and emphasizes the sunset, using red colors, Yellow, white and blue.

\section{Aesthetic values and method of implementation}

My oil

Mediator

\section{The set temperature}

The stabilization was fixed at a temperature of $500^{\circ} \mathrm{C}$

\section{Results:}

Through various experimental studies, they have reached:

The study of several of the following results:

1- Local colorants are thermal opaque dyes with a consistency

Dense and difficult to deal with except through the use of an intermediary

Suitable oil to melt it down to the right consistency for the application

On the surface of the glass, as the percentage of the medium increases, the transparency increases

The resulting color.

2- Depending on the type and amount of the medium used, we obtain

Multiple results that enrich the creative process and achieve values.

3- The diversity between non-traditional tools and brushes results from it

Great diversity in texture produced within the artwork.

4- Fixation temperatures play an important role in highlighting values

Aesthetics to work and through practical experiences has been reached

It is preferred to stabilize the colorants at a temperature range

$550{ }^{\circ}$ C. - from 480 .

\section{Recommendations:}

The research recommends the following: 
1- By making use of the pictorial values resulting from colourants, to raise the efficiency of handicrafts and industries Small in the field of glass

2- Taking advantage of local colorants and employing them to obtain Products that are comparable in quality to international products aesthetically and technically.

\section{References}

1- Jamal Mohamed Sayed Mohamed (2001) Study of texture in the work of Egyptian sculpture and its relationship to formation in different eras. Art Education College: MA - Helwan University.

2- Darty, L. (2004). The Art of Enameling: Techniques, Projects, Inspiration. U.S.A.

3- Mellonë, N. (2006). Painting with Enamels,Methods and techniques for painting figures with enamel modeling paints. Mithril Modelling Guides.

4- Eman Mohamed Wagdy EZZAT, EXPERIMENTAL PRACTICES TO DEVELOP FORMAL AND FORMATIVE PRINCIPLES FOR HANDICRAFTS, International Journal of Multidisciplinary Studies in Art and Technology, Vol. 1, No. 2, 2018, pp. 10-41.

5- Salah Shaaban Hassanin ABDEL RAHMAN, FORGING BY HAMMERING ON COPPER BETWEEN CRAFTSMANSHIP AND CREATIVITY, International Journal of Multidisciplinary Studies in Art and Technology, Vol. 1, No. 2, 2018, pp. 42-46.

Received: February 15, 2019

Accepted: April 20, 2019 